\title{
Ethnic Identity among Second-Generation Vietnamese American Adolescents
}

\author{
Tham $\operatorname{Tran}^{1}$ and Elizabeth Bifuh-Ambe \\ University of Massachusetts Lowell, USA
}

\begin{abstract}
Prior research shows that minority youths face many challenges as they develop their ethnic identity. These challenges include cultural conflicts (between home and school), language conflicts, and intergenerational conflicts. These conflicts may cause negative impacts on adolescents' self-identification, mental health, behavioral patterns, and tensions in family relationships. This qualitative study examines the development of ethnic identity in second-generation Vietnamese American adolescents. Data collection took place in the form of focus groups, individual interviews, observations, and free listing of eleven Vietnamese American adolescents and two parents at their homes and at a Buddhist youth program. The results suggest that within a structured youth program that validates their individuality, ethnic minority youths can develop a healthy sense of ethnic identity; and in the process, socio-cultural and intergenerational conflicts can be mitigated.
\end{abstract}

Keywords: Biculturalism, Buddhist youth program, conflicts, ethnic identity, mitigation.

The end of the Vietnam War saw the influx of Vietnamese immigrants into the United States, and the numbers have steadily increased from about 230,000 in 1980 to more than two million in 2017 (U.S. Census Bureau, 2017). Vietnamese immigrants who have resettled in the new land tend to maintain some of their traditional culture while adapting to American culture. This may cause difficulties of assimilation or acculturation, especially for the younger generations who were born in the U.S.A.

These younger generations face many conflicts that include but are not limited to cultural (between home and school), linguistic, and intergenerational norms and expectations (Schmidt, 1995; Trueba et al., 1993). These conflicts have negative impacts on adolescents' selfidentification and mental health (Ying \& Han, 2007), can potentially cause behavioral problems (Choi et al., 2008), and create tensions in family relationships (Ho \& Birman, 2010). Some researchers have suggested that interventions that help youths navigate these conflicts, such as being aware of the intergenerational gap, may strengthen bonds with parents and lead to healthier lifestyles (Choi et al., 2008; Lam, 2006; Nguyen et al., 2018). Existing literature suggests some research studies on positive youth development programs for minority youth. For example, Wang et al., (2017) used a mixed-methods design to examine the structure and content of character virtues among youth of color participating in Scouting programs through the Scoutreach initiative. The results show that participation in Scoutreach support youth of color to cultivate character virtues such as kindness, helpfulness, hope, tolerance, and community contribution. A qualitative study by Kegler et al. (2005), examines programs that can help adolescents mitigate

\footnotetext{
${ }^{1}$ Corresponding Author E-Mail: thutham1912@gmail.com
} 
cultural conflicts and facilitate their ethnic identity, suggesting that positive youth development programs help Vietnamese American youths strengthen their ethnic identity as well as help them avoid high-risk behaviors. However, research on how specifically second-generation Vietnamese American adolescents mitigate cultural conflicts and develop their ethnic identity is still scarce. There is a need for research that explores the multidimensional manifestations of ethnic identity amongst second-generation Vietnamese adolescents, and programs that can facilitate such development. Such bodies of knowledge would help empower Vietnamese youths, parents, and community stakeholders maintain healthy relations, which are vital for successful engagement in the socio-cultural, and socio-political matters of their country.

This study examined ethnic identity in second-generation Vietnamese American adolescents in a suburban city of the northeastern region of the United States.

The research questions were:

1. How is ethnic identity manifested among second-generation Vietnamese American adolescents?

2. How does a Buddhist youth program facilitate these youths' development of ethnic identity?

\section{Literature Review}

Erikson (1968) proposed that identity refers to the sense of self which individuals establish based on some unique and personal features and which makes them different from others. Personally, identity is considered as an individual manner reflecting how individuals perceive themselves through their involvement in relationships with their peers, family, school, and other social contexts. Socially, identity is constructed by others or by a particular collective group that individuals belong to. According to Ferrer-Wreder and Kroger (2020), identity is a person's driving force that makes them express their values, talents, needs, and interests in a personal way within a sociocultural context. Coulmas (2019) further explicates that individual identity is complexly fabricated by one's generic elements and other features that one has been exposed to and assimilated in their life such as: group memberships, loyalties, values, belief systems, and fashions. This fabrication may be subject to change depending on situations as the features may be changed, added, or abandoned. Identity development takes place throughout one's life (Coulmas, 2019; Erikson, 1968; Ferrer-Wreder \& Kroger, 2020; Marcia, 1966). However, adolescence is the most salient stage at which individuals are conscious of their changing identities (Ferrer-Wreder \& Kroger, 2020; Steinberg, 2008).

\section{Ethnic Identity in Minority Adolescents}

Among the many dimensions of identity, ethnic identity plays a significant role in how people perceive themselves and how others see them. Ethnicity usually refers to cultural aspects of a particular group that were passed on from generation to generation and are typical of that ethnic group (Phinney, 1996; Phinney \& Ong, 2007). The typical cultural features regarding ethnicity are customs, traditions, attitudes, beliefs, and behaviors. Ethnic identity is considered a multidimensional construct that serves as a framework of cognitive and information processing in which individuals envision things and people that they interact with. It reflects the way individuals use to develop knowledge, beliefs, and expectations about their ethnic group (Phinney, 1990; Phinney \& Ong, 2007). Ethnic identity also involves individuals' feelings of belonging to a particular group, their identification with some common features, values, and 
attitudes, shared by members of that ethnic group, (Keefe, 1992; Phinney et al., 1992). According to Phinney (1989), ethnic identity is influenced not only by one's inherited features such as traditions, language, religious practice, and cultural values, but also by one's present social contexts and interactions. Compared with majority ethnic youths, minority youths tend to be more concerned with ethnic identity since they are exposed to the discrepancy between their minority ethnic group's culture and the dominant culture of the majority ethnic group.

\section{Components of Ethnic Identity}

Researchers postulate three main components of ethnic identity: affection, cognition, and behaviors (Kwan \& Sodowsky, 1997; Peña et al., 2018; Phinney et al., 1992; Uba, 1994). Individuals' affection refers to their feelings of engaging with and belonging to their ethnic group. Cognitively, ethnic identity involves individuals' knowledge and awareness of cultural characteristics related to ethnicity such as cultural values, heritage language, history, and traditions. Behaviorally, individuals demonstrate ethnic identity by engaging in cultural activities and practices, such as speaking heritage language, eating ethnic foods, and practicing traditional conducts (Phinney et al., 1992).

Intergenerational cultural gaps can occur when there are discrepancies between parents and adolescents in terms of cultural expectations, and these conflicts may cause negative impacts on adolescents' mental health (Choi et al., 2008; Ho \& Birman, 2010; Nguyen et al., 2018; Ying $\&$ Han, 2007). These outcomes may lead to negative self-esteem that correlates with depression (Lam, 2005; Orth et al., 2014; Smokowski et al., 2014). Intergenerational cultural dissonance is also a predictor of attrition in positive parent-child bonding, which impacts family cohesion and satisfaction (Choi et al., 2008). Self-esteem involves self-oriented feelings of personal worth (self-construal), capacity, and self-assertion (Porter \& Washington, 1993). Self-esteem is also considered to be related to self-oriented cognitions, such as internal locus of control, persistence, and skills to face challenges (Koch, 2006; Porter \& Washington, 1993). While negative selfesteem has a strong correlation with depression, adolescents with positive self-esteem usually experience lower risks of depression (Lam, 2005; Nguyen et al., 2018; Orth et al., 2014; Phinney, 1990; Phinney et al., 1992; Smokowski et al., 2014).

\section{Methods}

The purpose of this qualitative research study is to understand how ethnic identity is manifested among Vietnamese American adolescents and how a Buddhist youth program plays a role, if at all, in facilitating these adolescents' development of ethnic identity.

\section{Participants}

Participants included 11 Vietnamese American adolescents enrolled in a Vietnamese Buddhist youth program and two parents of the adolescents. All adolescents are secondgeneration Vietnamese Americans. Among the participants, nine youths were born in the U.S., and two youths came to the U.S. before the age of five. The adolescents' ages range from 13 to 17. Six of youths are in middle schools and five of them are in high school. Participants have been involved in the program variously, ranging from 1 to 5 years. See Table 1 (Appendix A) for 
demographics of the youth participants. Both parents in this study are working class, firstgeneration Vietnamese Americans in their mid-forties.

\section{Setting}

The research site is a Vietnamese Buddhist temple that runs a youth program every weekend. This program is a non-profit organization, affiliated with Vietnamese Buddhist Youth Association (VBYA) in the U.S.A. The program was established in six years ago in response to Vietnamese parents' concerns about preserving their heritage culture. The program is fee-free for all youth members. Funding comes mostly from parents', and temple members' donation, and all youths volunteer their time without any financial compensations.

Table 2 (Appendix B) provides the typical weekly schedule of the Buddhist youth program. The program includes Vietnamese language learning, skill training such as Dharma, specialty activities like flower offering, singing and dancing, and preparation for special events of Buddhist and Vietnamese holidays such as Lunar New Year, Buddha's Birthday, Vietnamese Parents' Day, and Mid-Autumn Festival.

Based on the youth' age and gender, there are four different groups: (1) male pre-teen group (Oanh Vu Nam), which consists of boys age from 6 to 12; (2) female pre-teen group (Oanh $\mathrm{Vu} \mathrm{Nu}$ ), which consists of girls age from 6 to 12; (3) male teen group (Thieu Nam), which consists of teenage boys age from 13 to 17; and (4) female teen group (Thieu Nu), which consists of teenage girls age from 13 to 17.

\section{Ethics and Informed Consent Information}

The study went through the IRB review board of the university, that reviewed the process, granting the primary researcher approval to proceed with data collection. Parents and adolescent participants signed informed consent and assent forms and returned them prior to data collection. Issues related to potential conflict of interest and privacy relating to the primary researcher also being a youth mentor, were addressed at the beginning of each interview and free listing session.

Data collection was done both at the Buddhist temple and at the homes of participants. Data collection included participant observations, focus group interviews, free listing, and indepth one-on-one interviews conducted with two adolescents and two parents. Researchers used pseudonyms to anonymize the data and wiped clean all participant data of identifying items.

\section{Data Collection}

\section{Free Listing}

Free listing was used to understand how the Vietnamese adolescents think about learning Vietnamese (the heritage language) and Vietnamese culture in general. At the beginning of the Vietnamese language class, we informed the youth of the purpose of the research and passed out the worksheet with a prompt and space for them to write. The prompt asked the youths to write down a list of words to describe what they think about the Vietnamese heritage language learning within 5 minutes. In the following week, the second prompt asked the youth to write down a free list of what they thought about Vietnamese culture. After five minutes, they submitted the worksheets to the primary researcher and continued with their lessons. According to Borgatti (1999) typical domains have a core set of items mentioned by many respondents, while additional items represent the personal views of individuals. These guidelines were followed when using the 
data collected during free listing to provide some understanding of the adolescents' perceptions of their Vietnamese language learning and cultural values, and to construct emerging structured questions for the focus group interviews.

\section{Focus Group Interviews}

The goal of focus group interviews was to further understand Vietnamese adolescents' perceptions of the Vietnamese heritage language and Vietnamese cultural values through encouraging them to elaborate on the responses they provided in the prior free listing session. Some reading materials regarding Vietnamese cultural and traditional features were provided to stimulate discussions about these topics. Focus group sessions were recorded for detailed analysis. Two focus group interviews were conducted, each lasting 35 minutes.

\section{In-depth One-on-one Interviews}

In-depth semi-structured interviews were conducted at the participants' homes at their time of convenience. The home setting put the participants at ease and enabled them share their perspectives in a stress-free environment. In-depth semi-structured interviews of two youths (one teenage boy and a teenage girl), and the parents of both youths provided further perceptions of ethnic identity development in social contexts, and insights into any conflicts, if at all present, between parents and children. The interviews also delved into perceptions of the Buddhist youth program. All interviews were recorded and verbatim transcribed for data analysis.

\section{Data Analysis}

We used NVivo for data storage and analysis. Emergent themes were coded through constant comparison of the information. Nodes for all codes were made, and the primary researcher also wrote logs and memos for data interpretation.

\section{Researchers' Roles}

One of the researchers has served as a youth leader volunteer of the youth program since its establishment and has developed a good rapport with all participants (both youths and parents) for a long time, even before the research study began. According to Guillemin and Heggen (2009), rapport builds trust that helps both researchers and participants generate rich data and maintaining respect in the period of data collection especially in interviews and observations. However, to make sure that the rapport did not discount conflict and interest, at the beginning of the data collecting, the researcher briefly explained the research study to the participants and answered some questions regarding the study participation. She emphasized that their participation was completely voluntary, and they could choose to stop, skip any questions, or withdraw at any time during the research study; that they would remain anonymous; and all data provided by participants would be kept confidential through the use of pseudonyms.

In addition, the researchers remained conscious of potential conflict of interest throughout data collection and analysis, and used a variety of approaches for verification, validation, and confirmability of data. We ensured the dependability through triangulation of data sources and using member checking by asking the participants to check correction of the content interviews' 
transcripts and having discussions with them to ask their feedback on our findings along the course of this study. Participants, therefore had various opportunities to check authenticity of our work (Maxwell, 2005). We also employed researchers' reflective journal and assumptions bracketing to continuously ensure confirmability.

\section{Results}

\section{Components of Ethnic Identity}

Participants indicated some components of ethnic identity that could be found in prior literature such as self-identification, involvement in Vietnamese traditions and values, and positive attitudes toward Vietnamese heritage language.

\section{Self-identification}

All the youths in the study reported being proud of their Vietnamese heritage and values. They identified with Vietnamese culinary traditions and saw the value of sharing meals together as a way of bringing family members closer together and accounting for harmony. Youths also felt ethnic pride and were willing to share their traditions with peers from other cultures. They acknowledged that it is essential to have self-identification. Quynh (pseudonym), a teenage female participant stated: "It's good to know what you identify as, in life because sometimes, you know, it's hard to understand. It's good to know where you stand in the world."

Ethnicity. Almost all participants in this study showed awareness of ethnicity by identified themselves as Vietnamese Americans. Only one teenage boy, Danny (pseudonym), said he wants to identify as Vietnamese, not American, because he came to the U.S. at the age of four. Danny explained: "I would say [myself] Vietnamese because I was born in Vietnam, so I consider myself as Vietnamese."

When asked if they sometimes wanted to simply identify as Americans only, all the youths answered "no." They all showed themselves to be proud of the Vietnamese values and confirmed that they wanted to share their knowledge of Vietnamese ethnicity with their peers and others. Quynh commented: "Sometimes like you know we in school, we learn about Asian culture, so whenever we learn about Vietnam, I like to put my input as a Vietnamese American."

Family bonds. Family bonds, created through the enjoyment of good food, can bring harmony and closeness to the family and relationships. Anh, a teenage girl, reported that her mom usually cooks for her and her dad with her heart, and they enjoy the food her mom cooks with appreciation and love. Such interactions around food, helps bring closeness as a family. The other girls, Yen and Quynh, added that their extended family usually gets together to enjoy food on special occasions and holidays through which they build close bonds.

Ethnic cuisine. The youths also identified as Vietnamese through culinary traditions and cuisine. During focus group 2, Hieu (pseudonym) commented: "I'm mainly Vietnamese because I love Vietnamese cuisine... American cuisine is full of oil and fat, but Vietnamese [cuisine] is very complex and delicious." Yen added:

I would say what the different types of food we have and that it's much less salty than American food and the different herbs we add like in Pho, we have different herbs, like Vietnamese mints, and we add different things in it. 
All the youths were excited naming a variety of Vietnamese staples, such as rice, vegetables, and fish sauce. Brady said: "My favorite Vietnamese food is like rice mostly and then when you add different flavors and then mix up the flavors. You play with the flavors. It can be very good like a common "cơm ba màu" [mixed three-color rice]."

Regarding utensils, the youths added that rice-cookers and chopsticks are always available in Vietnamese family kitchens, and they have all known how to use chopsticks since they were young. Yen commented on many kinds of chopsticks her family has: "We have the long ones, the long wooden ones, the short wooden ones, metal ones, and plastic ones. Wow plastic, but like they're like hard but they're not actually plastic. Total four in types!"

Identification with Vietnamese ethnicity was evidenced through many social aspects associated with their lives, such as eating, school interactions, familial interactions, and other customs and traditions, such as respect for elders and teachers, and getting along with siblings and others. The two parents in the interviews also emphasized that a respectful manner is one crucial thing they expect their kids to enact in the relationship with the elders. Hoa, Quynh's mom, explained,

Just like our [Vietnamese] culture, we have to be polite; we always have to respect elders. I always tell Quynh that she has to behave like that not only with her grandparents at home, [but also with any elders] when she goes out to anywhere.

Participants all emphasized the traditional expectation of taking care of their parents at home when they get old and keeping family ties with extended family members. Parents also expect older children to help in raising their younger siblings; and taking more responsibility towards being role models for the younger ones. Following the parental expectations, some youths in the study stated that they usually help as care givers for younger siblings and elders.

\section{Interactions at School}

Attitudes and values learned at home appear to translate well in the school environment. Youths reported that at school, they respect their teachers and get along well with friends. These character traits build trust and makes it easier for the youths to reach out to the right people to ask for help when needed. Regarding relationship with teachers and students at school, Quynh stated,

The relationship between me and my teachers is pretty good. The class is pretty small, so it's easier to communicate and talk to the teachers... I talk to a lot of the students. I think I've talked to all the people in my class at some point in the day.

Hieu added, "I get along with everyone at school."

Trust and proximity towards teachers and peers help with finding solutions to challenging school tasks. According to Hieu,

I get help from the teachers and sometimes from friends because I feel like it's hard to understand sometimes what we need to write. It's just 
sometimes like in ELA you have to write something and it's hard to get the idea out. I just ask and learn more. I usually finish the paper well.

\section{Participation in Vietnamese Traditions}

Most of the youths professed that they liked to participate in Vietnamese traditional events such as Lunar New Year (Tet), Mid-Autumn festival (Tet Trung Thu), and Vietnamese Parents' Day. About the meaning of Lunar New Year: Quynh explained: “Tet is an occasion you [and] your family members gather and give some wishes to elder one and those are some customs and values of Vietnamese people."

All the youths in the focus group 2 could remember and discuss the Vietnamese traditions costumes such as Ao Dai (long dress), Non-La (leaf hat), and Ao Ba Ba (loose-fitting southern blouse). They said they all like wearing these traditional clothes on Vietnamese traditional events. Yen proudly stated, "Maybe like the Ao Dai, the traditional Vietnamese dress is probably better than any other dress I would wear."

\section{Biculturalism}

While the youths acknowledge their Vietnamese ethnic identity, they were also aware of the dominant culture that they live in. Quynh explained: "I Just describe myself as Vietnamese American because I think that I know the language and understand most of it, but since I was born in America, I don't understand most of the [Vietnamese] culture or background that went on."

The youths stated that they absorbed American culture through learning at school, making friends with American peers, watching TV, and using social media. Hieu added that his identity was formed by parents, friends, and social media:

They [my parents] shaped my discipline. They shaped how I do in school because they want me to do my best in school... My identity is formed by my friends and social media since where we are right now, social media is a big impact on daily life so that's where mostly everybody's identity is found especially the youths.

Youth participants reported no difficulties navigating two different cultures successfully in various contexts, one American culture at home, and another Vietnamese culture at home. As to how they position themselves towards their biculturalism, youth participants indicated that they just react or behave automatically depending on the contexts they encounter. When asked what she thinks it means to be Vietnamese American, Quynh answered that "I think it means to have some aspects of both sides sometimes you can be both and I think it's important."

\section{Youths'Attitudes Towards Vietnamese Heritage Language}

As a crucial part of Vietnamese ethnicity, parents encourage the use of the Vietnamese language at home. Youths attending the Buddhist youth program are aware of the values of their Vietnamese heritage language and aspire to use it fluently. The youths find a sense of fulfillment in communicating well with the elderly members of their families who cannot speak English.

Both parents interviewed, expected their children to use the Vietnamese language at home. They said that they all communicated with their children in Vietnamese, however, with 
time, as the youths started school, they tended to show a preference for English instead of Vietnamese although their parents continued talking to them in Vietnamese. Thuy (pseudonym for one of the parent participants) stated that the temple and youth group had helped improve their children's Vietnamese fluency, and frequency of usage of the language. She could now communicate with her children in Vietnamese about almost any topic at home:

When they [her children] were very young, they spoke Vietnamese. Then when they were 5 or 6 years old, they went to school and started speaking English. But at home, I also had to speak Vietnamese for the kids to learn more Vietnamese, but actually staying at home, they didn't not learn as much as they do in the GDPT (Buddhist youth program). They come here (Buddhist youth program) and go to the temple; they speak Vietnamese much better and speak more than before (Thuy).

Hoa, another mother, was confident that, thanks to the Youth Program, her daughter, Quynh is fluent in Vietnamese:

There are some things that we have to speak English because I myself do not know what it is called in Vietnamese, so I have to speak English (smiling). But sometimes it is she (Quynh) knows more than me. Sometimes, I'm surprised that she knows things that I don't even remember in Vietnamese.

Quynh, also confirmed that thanks to learning Vietnamese language at the Buddhist youth program, now she can not only speak the language fluently but can also read and write it quite well: "I mainly use Vietnamese at home... some English when our friends or somebody who doesn't know Vietnamese, I talk in English... I'm pretty fluent [in Vietnamese]. I feel like I can go to Vietnam and live there and talk."

Some youth participants stated that the Buddhist youth program had helped them become more confident using Vietnamese to talk to their parents at home, making their Vietnamese language sound more natural. Quynh explained,

I think it's helpful to me. It's helped me learn like new words and I can understand my mom more when she speaks instead of asking her 'What does that mean?" I know what word she is saying. I know what phrases she's asking me, and it's made my Vietnamese better anyway.

Brady and Hieu said that learning Vietnamese language well, could improve their job prospects. Brady commented:

Like learning Vietnamese language, it can help you like get you a better job because like a lot of people can be Vietnamese, so they need you to like talk to other people and then they can't talk. You can be a translator and then it also can help like keep the tradition of Vietnamese. You don't want to forget Vietnamese because it's like a very unique language (Brady). 
Danny simply said Vietnamese language is "cool" to him because he can be bilingual.

\section{The Role of the Buddhist Youth Program in Facilitating the Youths' Ethnic Identity Development}

\section{A Source of Cultural and Spiritual Facilitation}

Both parents and youth participants in the study indicated that the Youth program was valuable both as a source of Vietnamese cultural values and spirituality. Words used to describe the program included: "useful" (three times), "fun" (three times), and "interesting" (two times). Other words and phrases used once included "laughable," "helpful in the long run," "easy," amazing," "awesome," "inspiring," "speakable," "epic," "wisdom," "meaningful," "cultural," "adventurous," "unstressful," "can talk to your parents," and "can teach your children Vietnamese."

Youths appreciated the caring, non-judgement, inclusive and fun environment at the center that helped them strengthen friendships, and bonds between students and families bonded with each other. Thuy, one of the mom's interviewed, said: "I like GPDT (the Buddhist youth program) because it is like sociable, fun and everyone treats others very nicely. They come here to learn about Buddhism, just like a family, and I really like it." Youth leaders not only mentor students at the temple but are also very active in special occasions like graduations and birthdays.

Quynh summarized it as "a program where everybody is friends with each other and just builds that relationship. I feel like everyone is kind."

When asked what things they want to change about the Buddhist youth program. Quynh said she only wished more members would join the Buddhist youth program because there will be "more people to bond with and to hang around."

\section{Youth Leaders as Role Models}

Both parents are youths considered youth leaders as role models. Thuy said,

The leaders are teaching the kids many things, and in general, the leaders are always good because they lead the kids to the right path and help them to make the right decisions. The kids are learning a lot from the leaders.

According to the parents, the youth leaders do well in cultivating good habits in the youths by practicing punctuality and integrity. Hoa believed that it is not easy to build trust and cooperation from the youths, so the youth leaders must have worked hard to be able to gain the young people's trust.

Youths'participation in the program helped them build skills, and helped participants develop self-confidence.

Both parents reported that since joining the program, their children had become e respectful towards parents and do not talk back. Hieu's mom says:

Hieu has improved a lot. First, he has more understanding about

Vietnamese. Second, he becomes more understanding for parents. Third, 
he knows how to listen to adults and doesn't talk back. In general, he has been very good.

Besides, Hieu's time spent playing games online has been much decreased and his school grades much improved. His grades have been stable and much better than before he attended the Buddhist youth program:

In the past, it was not very satisfying, his grades were bad, but now in general he has improved a lot and I'm satisfied with it.

Quynh's mom indicated that Quy had become more responsible and mature since attending the Buddhist youth program;

Quynh usually makes her bed nicely after she gets up; cleans up house voluntarily; takes good care of her younger brother and helps him with his homework.

\section{Youths’ Perspectives on Social Skills}

The youths themselves acknowledged positive changes in their personality and behaviors. Quynh says she is has become more outgoing: "[I $\mathrm{am}]$ definitely not shy talking to new people anymore. I'm more outgoing." Quynh added that her social and communication skills have been improved thanks to joining the Buddhist youth program. She especially likes participating in dancing and singing performances, which have helped her develop her artistic skills. Quynh says:

I've [learned] some skills like leadership skills, survival skills like Morse code and trail marks, artistic skills, you know how to dance right and sing. I think those are good for me.

According to Hieu, most of the youths' confidence stems from many activities such as meditation practice, and focused leadership and social skills training. "...My favorite survival skill that I learned here is Morse code. It's just fun to do. It's like a challenge to your brain."

\section{Discussion}

The results of this study underscore the vital role of family and well-structured community programs in preserving traditional ethnic values of new immigrant youths within the U.S., specifically first and second generation Vietnamese American youths. Parents' practice of desired values at home and expectations towards their children shape the ways that youths behave in family settings and other social interactions. Learning the Vietnamese heritage language and engaging in structured group activities at the Buddhist Temple, also served as catalysts to support Vietnamese youths as a they develop and strengthen their ethnic identity. These results align with the findings of Phinney et al. (2001) that all three factors of ethnicity: language, parents' cultural maintenance, and in-group peer interaction contribute substantially to the ethnic identity of the minority adolescents. 
Both youths and parents in this study reported experiencing some of the conflicts indicated in prior research such as inter-generational, socio-cultural of peer conflicts (Choi et al., 2008; Ho \& Birman, 2010; Guney, 2013; Kim, 2014; Lam, 2006; Phan, 2005; Umana-Taylor et al., 2006; Ying \& Han, 2007); but also admitted that the Buddhist Youth program mitigated those conflicts. Previous researchers pointed out that immigrant parents usually adhere to traditional cultural values while their children tend to adopt the mainstream values and lifestyles and ignore their cultures of origin (Choi et al., 2008; Ho \& Birman, 2010). This acculturation dissonance is usually the cause of intergenerational conflicts in immigrant youths, which lead to disruptive parent-child relations, often resulting in undermining support and placing youths at higher risk for behavioral problems. The youth program serves as a bridge of communication between parents, (the guardians of ethnic cultures) and the American cultures that youths constantly interact in; helping youths through programs, to become more aware of, and respectful of their ethnic cultural values, while embracing healthy aspects of the American mainstream cultures.

Embracing the values of both cultures ethnic and the U.S. mainstream results in ownership of a bicultural identity in the youths, which has many positive outcomes, for selfconstrual: an individuals' perceptions of self as interacting with others and socio-emotional factors (Olalowo, 2020; Lam, 2006).

\section{Conclusion}

Lessons learned from this study, such as the positive impact of the Buddhist youth program, could be used as recommendations for providing similar youth development programs that can facilitate ethnic identity development in other ethnic minority new immigrant groups. By extension, U.S public schools should also infuse Multicultural education into the k-12 curriculum; that would create opportunities for immigrant youths to share their cultures and empower them, while widening the knowledge bases s of U.S. K-12 mainstream students to the values and richness in other cultures. Often, such studies are delayed until college level, when it is almost too late, as most students may have already made up their minds about cultural superiority or perceived inferiority. Encouraging new immigrant students to share their cultures in class projects or activities, may also boost minority students' development of self-esteem and motivation which research shows, boosts academic outcomes in all school subjects (Orth et al., 2014). More heritage languages should be provided as foreign language classes at K-12 levels, not only to preserve bilingualism and biculturalism, of immigrant youths, but also increase the benefits of bilingualism to other U.S. mainstream youths. According to Charlemagne the Roman Emperor (c.742-814), "to have another language is to possess a second soul."

Lastly, community-based organizations like the Buddhist youth program in this study should be recognized as shareholders of extra-curricular educational programs that students from all ethnic backgrounds are encouraged to participate in. Although this study was conducted on a limited number of participants within a specific research context and the finding may not be generalizable in broader sections of the population, the study can be replicated in other contexts for applicability. 


\section{References}

Borgatti, S. P. (1999). Elicitation techniques for cultural domain analysis. In J. Schensul \& M. Lecompte (Eds.), Enhanced ethnographic methods: Audiovisual techniques, focused group interviews, and elicitation techniques (pp. 115-151). AltaMira Press.

Bureau, U.S. Census (2017). Total Asian Alone or in Any Combination Population (the Total Groups Tallied) 2015 American Community Survey 1-Year Estimates. Retrieved 1 August 2020, from https://www.census.gov/history/pdf/acs15yr-korean62017.pdf.

Choi, Y., He, M., \& Harachi, T. W. (2008). Intergenerational cultural dissonance, parent-child conflict and bonding, and youth problem behaviors among Vietnamese and Cambodian immigrant families. Journal of Youth \& Adolescence, 37(1), 85-96.

Coulmas, F. (2019). Identity: A very short introduction. Oxford University Press.

Erikson, E.H. (1968). Identity: Youth and Crisis. New York: W.W. Norton Company.

Ferrer-Wreder, L., \& Kroger, J. (2020). Identity in adolescence: The balance between self and other (4th ed.). Routledge.

Guillemin, M., \& Heggen, K. (2009). Rapport and respect: Negotiating ethical relations between researcher and participant. Medicine, Health Care, \& Philosophy, 12(3), 291-299.

Guney, N. (2013). Preferences of Turkish Language Teachers for the Assessment-Evaluation Tools and Methods. Educational Research and Reviews, 8(15), 1263-1269.

Ho, J., \& Birman, D. (2010). Acculturation gaps in Vietnamese immigrant families: Impact on family relationships. International Journal of Intercultural Relations, 34(1), 22-23.

Keefe, S.E. (1992). Ethnic identity: The domain of perceptions of and attachment to ethnic groups and cultures. Human Organization, 51 (1), 35-43.

Kegler, M. C., Young, K. H., Marshall, L., Bui, D., \& Rodine, S. (2005). Youth development program: Positive youth development linked with prevention in a Vietnamese American community: Successes, challenges, and lessons learned. Journal of Adolescent Health, 37(Supplement), S69-S79.

Kim, J. (2014). "You don't need to be mean. We're friends, right?": Young Korean-American children's conflicts and references to friendship. Journal of Early Childhood Research, 12(3), 279-293.

Koch, E. J. (2006). Examining the role of self-esteem in psychological functioning and wellbeing. In M. H. Kernis (Ed.), Self-esteem issues and answers: A sourcebook of current perspectives (pp. 260-266). Psychology.

Kwan, K.- L. K., \& Sodowsky, G. R. (1997). Internal and external ethnic identity and their correlates: A study of Chinese American immigrants. Journal of Multicultural Counseling \& Development, 25(1), 51-67.

Lam, B. T. (2005). Self-construal and depression among Vietnamese American adolescents. International Journal of Intercultural Relations, 29(2), 239-250.

Lam, B. T. (2006). Self-construal and socio-emotional development among Vietnamese American adolescents: An examination of different types of self-construal. International Journal of Behavioral Development, 30(1), 67-75.

Marcia, J. E., (1966). Development and validation of ego identity status. Journal of Personality \& Social Psychology, 3, 551-558.

Maxwell, J. A. (2005). Qualitative research design: An interactive approach (2nd ed.). Sage Publications. 
Nguyen, D. J., Kim, J. J., Weiss, B., Ngo, V., \& Lau, A. S. (2018). Prospective relations between parent-adolescent acculturation conflict and mental health symptoms among Vietnamese American adolescents. Cultural Diversity \& Ethnic Minority Psychology, 24(2), 151-161.

Olalowo, I. E. (2020). Accounts and Thoughts of Overage Children: A Qualitative Study on the Physical and Emotional Environment of Preschools in Ibadan, Nigeria. American Journal of Qualitative Research, 4(3), 1-13. https://doi.org/10.29333/ajqr/8390

Orth, U., Robins, R. W., Widaman, K. F., \& Conger, R. D. (2014). Is low self-esteem a risk factor for depression? Findings from a longitudinal study of Mexican-origin youth. Developmental Psychology, 50(2), 622-633.

Peña, C., Jones, L., Orange, A., Simieou, F., \& Márquez, J. (2018). Academic success and resiliency factors: A case study of unaccompanied immigrant children. American Journal of Qualitative Research, 2(1), 161-181. https://doi.org/10.29333/ajqr/5797

Phan, T. (2005). Interdependent self: Self-perceptions of Vietnamese American youths. Adolescence, 40(158), 425-441.

Phinney, J. S. (1989). Stages of ethnic identity development in minority group adolescents. Journal of Early Adolescence, 9, 34-49.

Phinney, J. S. (1990). Ethnic identity in adolescents and adults: Review of research. Psychological Bulletin, 108, 499-514.

Phinney, J. S. (1996). Understanding ethnic diversity: The role of ethnic identity. American Behavioral Scientist, 40, 143-152.

Phinney, J. S., \& Ong, A. D. (2007). Conceptualization and measurement of ethnic identity: Current status and future directions. Journal of Counseling Psychology, 54(3), 271-281.

Phinney, J. S., Chavira, V., \& Williamson, L. (1992). Acculturation attitudes and self-esteem among high school and college students. Youth \& Society, 23, 299-312.

Phinney, J. S., Romero, I., Nava, M., \& Huang, D. (2001). The role of language, parents, and peers in ethnic identity among adolescents in immigrant families. Journal of Youth \& Adolescence, 30(2), 135-153.

Porter, J. R., \& Washington, R. E. (1993). Minority identity and self-esteem. Annual Review of Sociology, 19(1), 139-161.

Schmidt, P. R. (1995). Working and playing with others: Cultural conflict in a kindergarten literacy program. Reading Teacher, 48(5), 404.

Smokowski, P., Evans, C., Cotter, K., \& Guo, S. (2014). Ecological correlates of depression and self-esteem in rural youth. Child Psychiatry \& Human Development, 45(5), 500-518.

Steinberg, L. (2008). A social neuroscience perspective on adolescent risk-taking. Developmental Review, 28(1), 78-106.

Trueba, H.T., Cheng, L, \& Ima, K. (1993). Myth or Reality: Adaptive Strategies of Asian Americans in California. Washington, DC: Palmer Press.

Uba, L. (1994). Asian American: Personality patterns, identity, and mental health. Guilford Press.

Umana-Taylor, A. J., Bhanot, R., \& Shin, N. (2006). Ethnic identity formation during adolescence: The critical role of families. Journal of Family Issues, 27(3), 390-414.

Wang, J., Champine, R., Ferris, K., Hershberg, R., Warren, D., Burkhard, B., Su, S., \& Lerner, R. (2017). Is the Scoutreach Initiative of Boy Scouts of America linked to character development among socioeconomically, racially, and ethnically diverse youth: Initial explorations. Journal of Youth \& Adolescence, 46(10), 2230-2240.

Ying, Y.W., \& Han, M. (2007). The longitudinal effect of intergenerational gap in acculturation on conflict and mental health in southeast Asian American adolescents. American Journal of Orthopsychiatry, 77(1), 61-66. 


\section{Notes on Contributors}

Tham Tran received her Ph.D. in Curriculum and Instruction, with specialization in Language Arts and Literacy Studies, from the University of Massachusetts, Lowell. Her scholarship is on the bilingual and bicultural identities of immigrant youths, multicultural education, and positive youth development. She has presented at many conferences and has served as the Youth leader of the Vietnamese Buddhist Youth Association in the World. She has also served as a lecturer at the Department of Foreign Languages in HUFLIT University, Ho Chi Minh City, Vietnam.

Elizabeth Bifuh-Ambe is Associate Professor at the College of Education, University of Massachusetts, Lowell, where she teaches courses in Literacy Development and Diversity. She also facilitates workshops for k-12 teachers. Prior to joining UML, she taught at elementary, middle, high school, and universities across Africa and the U.S.A. While serving as a UNICEF consultant, she became aware of the low literacy rates of girls in some parts of Africa and the globe and has devoted herself to improving literacy rates for marginalized populations, the world over. She considers herself a global citizen. Elizabeth Bifuh-Ambe can be reached @ Elizabeth_ambe@uml.edu. 


\section{Appendix A}

Table 1

Demographic Chart of Youth Participants (pseudonyms)

\begin{tabular}{|c|c|c|c|c|c|c|}
\hline & Participant & Gender & Age & Place of birth & $\begin{array}{c}\text { Grade at } \\
\text { school }\end{array}$ & $\begin{array}{c}\text { Years of } \\
\text { participation }\end{array}$ \\
\hline 1 & Brady & Male & 13 & US & 7 & 4 \\
\hline 2 & Cuong & Male & 13 & US & 6 & 3 \\
\hline 3 & Tam & Male & 14 & US & 8 & 1 \\
\hline 4 & Danny & Male & 15 & Vietnam & 9 & 4 \\
\hline 5 & Hoang & Male & 13 & Vietnam & 6 & 5 \\
\hline 6 & Duc & Male & 13 & US & 7 & 5 \\
\hline 7 & Hieu & Male & 16 & US & 10 & 5 \\
\hline 8 & Quynh & Female & 14 & US & 8 & 4 \\
\hline 9 & Yen & Female & 13 & US & 6 & 3 \\
\hline 10 & Anh & Female & 17 & US & 11 & 1 \\
\hline 11 & Mai & Female & 14 & US & 9 & 1 \\
\hline
\end{tabular}




\section{Appendix B}

\section{Table 2}

Weekly Schedule at the Buddhist Youth Program

\begin{tabular}{|c|c|}
\hline $1: 00 \mathrm{pm}$ & Sitting meditation and chanting \\
\hline $1: 30 \mathrm{pm}$ & Association anthem, attendance, weekly story \\
\hline $1: 40 \mathrm{pm}$ & Group meeting \\
\hline $2.00 \mathrm{pm}$ & Vietnamese language \\
\hline $3: 00 \mathrm{pm}$ & Break and snack time \\
\hline $3.30 \mathrm{pm}$ & Dharma/specialty activities/general knowledge \\
\hline $4.30 \mathrm{pm}$ & Group bonding, circle games \\
\hline $5.00 \mathrm{pm}$ & Dismissing \\
\hline
\end{tabular}




\section{Appendix C}

Material used for discussion in focus group interviews.

\section{Food and Diet} Food is a very important part of Vietnamese culture. The Vietramese not only enioy eating but
believe eating good food can bring harmony and closeness to the family and relationships. The
types of foods are chosen to bring luck and these vary from province to province.

Shopping daily for fresh food is essential for all Vietnamese cooking. In general, Vietnamese people are not as concerned about nutrition as Westem people. They are more concerned with the food's texture, flavour, colour and aroma.

Vietnamese cuisine is known for using fish sauce, soy sauce, rice, fresh fruits and vegetables and herbs and spices including lemon grass, lime and kaffir lime leaves. Throughout all regions of Vietnam, the emphasis is always on serving fresh vegetables and herbs as side dishes along with dipping sauce. The most common meats used in Vletnamese cuisine are pork, chicken, shrimp, cockles and various other kinds of seafood. Beef is usually used for one of the most popular dishes in Vietnam, 'pho soup' and the 'seven course beef' dish.

A typical meal for the average Vletnamese family could include individual bowls of rice; boiled. grilled steamed, stir fried or stewed meat, fish or other seafood; a stir-fried, raw or steamed vegetable dish; soup and fish sauce or soy sauce for dipping.

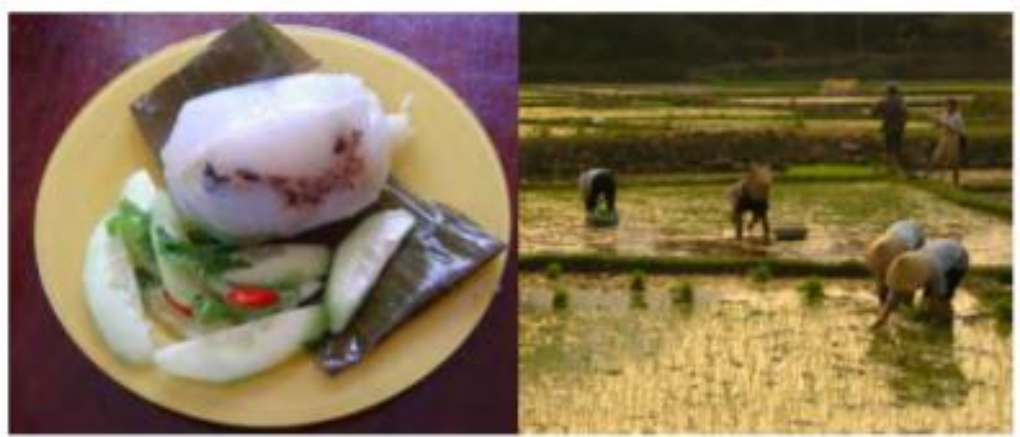

Meals:

Breakfast - is preferably rice or noodles with milk, and some older people enjoy a bread roll prepared from rice flour.

Lunch - could consist of pork, chicken or fish with noodles or rice. (Vietnamese people do not eat lamb.) Soup for lunch is desirable but preferably separate containers for the soup and rice.

Afternoon tea - should be checked with the resident They might be interested in eating a piece of cake and drinking herbal or green tea.

Dinner - is the main meal and should be rice, a meat dish and vegetables and should not be a sandwich.

Source: Goldman, C. (2009). Vietnamese cultural profile. Diversicare. 
Journal of Ethnic and Cultural Studies

Copyright 2021

2021, Vol. 8, No. 2, 167-186

ISSN: 2149-1291

http://dx.doi.org/10.29333/ejecs/622

\section{Food and Diet}

The most popular Vietramese dishes include:

- Noodle dishes - 5pecial Vietnamese noodles should be used which are extremely thin and woven into intricate bundles (e.g. Banh Hol, Bun cha, Mi Quang or Bun thit nuang)-

- Noodle soups - A common characteristic of many of these soups is the rich and very tasty broth (e.g. Pho, Bun bo Hue, Bun Mang, Bun Oc or Bun rieu). The most popular is pho-a noodle soup. There are many varleties of pho made from different types of meat but it is most commonly beef and chicken.

- Rice dishes - There are numerous types of meat prepared in various ways that are served with the broken rice. The rice and meat are served with various greens and pickled vegetables, sometimes with a prawn paste cake and grilled prawns (e.g. Com chien Ducng Chau, Com hen or com tam).

- Sticky rice dishes - The general idea is sticky rice with coconut milk, cooked the same way as the rice or steamed for a firmer texture and more flavour (e.g. Banh chung or Xol ).

- Wraps and rolls - Rice flour rolls are stuffed with ground pork, prawns and wood ear mushrooms (e.g. Bdnh cuon or Blanh trang are made from 'rice paper' - thin rice flour sheets).

- Meat dishes - examples of these include beef and vegetables stew with spicy herbs (Bo kho), and cubed, marinated beef served with green vegetables, onion and tomato (Boluc lac).

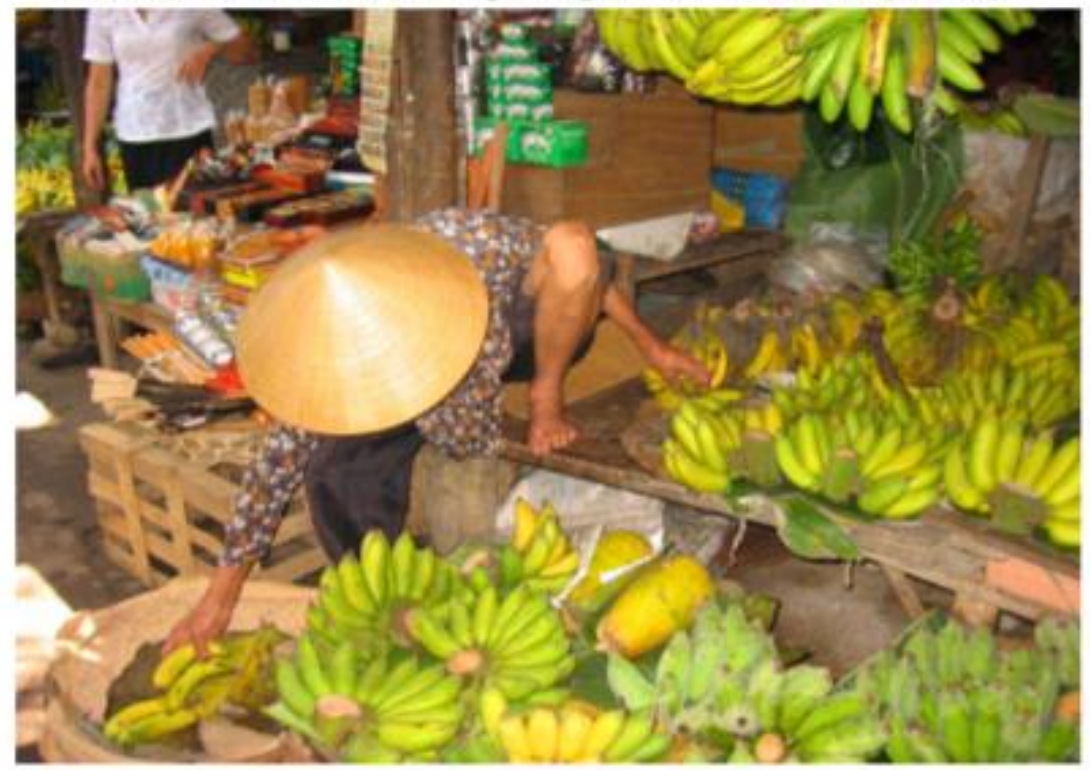

Source: Goldman, C. (2009). Vietnamese cultural profile. Diversicare. 


\section{Appendix D}

\section{Focus Group Protocol}

\section{Focus group 1}

1. Why do you like learning Vietnamese?

2. How important it is for you to be fluent in Vietnamese language? Can you please share your own experiences?

3. Do you like the way you are learning Vietnamese heritage language at the Buddhist youth program? What other activities do think should be added in Vietnamese language class?

4. How often do you use Vietnamese?

5. Do you think you can understand and communicate with your parents/grandparents better through using Vietnamese?

6. What outcomes do you think you can have from being fluent in Vietnamese?

7. Is there anything else you would like for me to know?
1. What do you think of Vietnamese cuisines?

2. What Vietnamese food do you like? How often do you eat Vietnamese food?

3. The research states that Vietnamese people do not only enjoy eating but believe eating good food can bring harmony and closeness to the family and relationships. In your experience, do you think it is right?

4. If a person who has never tried Vietnamese food before, what cuisines would you suggest them to eat? Why?

5. Which do you like better, Vietnamese cuisines vs American cuisines? Why?

6. What salient things you want to share if someone ask you about Vietnamese culture?

7. Do you identify yourselves as Vietnamese American? In what ways?

8. What cultural values do you and your family still maintain?

(respecting elders, worshipping ancestors, doing good deeds, hardworking etc.)

9. What Vietnamese cultural activities do you participate in?

10. What Vietnamese traditional costumes do you wear? On what occasions?

11. Is there anything else you would like for me to know? 